\title{
Mathematical and Analytical Models of the Market of Commercial Real Estate: Monitoring, Analysis and Projected Growth in the Context of Clusterization
}

\author{
Elena Klochko, ${ }^{1, *}$ Kristina Karpenko,a
}

\author{
${ }^{1}$ Department of Management, Kuban State Agrarian University, Krasnodar, Russia \\ ${ }^{2}$ Department of Finance and Accounting, Institute of Service, Tourism and Design (Branch) of North Caucasus Federal \\ University, Pyatigorsk, Russia \\ ${ }^{a}$ Email: rbcz79@mail.ru \\ *Corresponding author. Email: magadan.79@mail.ru
}

\begin{abstract}
The present article is primarily aimed at developing the model for analysing and forecasting the development of the commercial real estate market. The authors have studied the existing methodology for the analysis of the real estate market and its weaknesses, and have identified the areas of further development of the models for analysing and forecasting the development of the commercial real estate market. It has been found that the assessment of the current situation in the real estate market is performed based on static and historical data, which, however, do not always provide full information. Therefore, it is advisable to use index methods as an additional data processing instrument - they empower analysis, albeit increasing its complexity. The authors have revealed that a formalized description of the procedure for building discrete spatial and parametric models of the real estate market is performed in comparison with the approaches and concepts of a related methodology regression modelling with continuous arguments. Additionally, the article presents the authors' dynamic model of the real estate market for the Caucasian Mineralnye Vody region.
\end{abstract}

Keywords: cluster structures, real estate market, index methods, economic and mathematical algorithm,

analytical models

\section{INTRODUCTION}

The real estate market is an indispensable element of territorial clusters. In the process of managing the development of territorial cluster structures, there is a clear need to analyse and forecast the key indicators of the real estate market in order to formulate plans and strategies for cluster development, identify a temporal trend in changes of its main characteristics and indicators, set the course for cluster functioning and develop a flexible regional socio-economic and tax policy.

The analysis of the real estate market allows determining the feasibility of using a certain real estate unit (or a lot with improvements made) to make profit in the conditions of a particular market. Within the territory clustering process, the real estate market analysis identifies the feasibility of using commercial real estate units to generate profit for the purpose of cluster creation, operation and development.
The value of the real estate market analysis is measured by its degree of its reliance on statistical data. The assessment of the current situation also addresses historical data, which, however, do not always provide full details. Therefore, for better data processing, it is advisable to apply index methods - they empower analysis, albeit increasing its complexity.

The models of broad assessment of real estate are found in the research by I.N. Anisimova, N.P. Barinov, S.V. Gribovsky [1], and S.L. Bondarchuk [2]. The analyses carried out in their works allowed identifying the shortcomings of these models. M.A. Fedotov, S.V. Gribovsky, and G.M. Sternik developed the methodology for the analysis of the real estate market, the economic and mathematical algorithm, which collects accurate and statistically reliable results for individual and broad assessment of real estate [3]. Their research laid the foundation for the present study - the authors have adapted the model proposed by G.M. Sternik [4] and applied it to the analysis and forecast of the development of the commercial real estate market. 


\section{METHODS}

The idea to adapt index methods to the real estate market was first put forward by Sternik G.M in 1995 [5]. His methodology is widely applied by market analysts and international organizations (e.g. CEREAN).

The indices of the real estate market are divided into three groups, each of them having several market indicators: 1) price indices (Real Estate Price Index REPI); 2) volume indices (Real Estate Transaction Index - RETI); and 3) market capacity indices (Real Estate Income Index - REII).

The considerable merits of the index method include the following: 1) simplicity of data presentation, 2 ) the possibility of presenting the dynamics of several values that are incomparable in physical terms in one graph, 3) the possibility to identify time series patterns and examine the causes affecting the dynamics of time series.

A more profound analysis of the real estate market development and its more accurate forecast can be provided if mathematical models based on the identified patterns of process under study are used. The heuristic approach to forecasting real estate prices implies a logical, quantitative and qualitative analysis of the factors that create price trends, and identification of the overall trend.

As research have shown, there is a common tendency for the emerging markets: the prices for real estate in cities are growing from the initial, pre-market values to the level of the world market prices that correspond to the prices of cities with mature markets. In certain periods, this growth may decelerate due to deteriorating socio-economic conditions in the region, greater population outflow, etc. However, the prices gradually flatten out and follow general economic, investment, and migration cycles.

The essence of this tendency is that the real estate market passes through a number of stages in its development, with numerous factors changing through stages: the initial price level, the ratio of the primary and secondary real estate market prices, supply and demand ratio, buyers' and sellers' market behaviour, market activity rate, legal environment, market infrastructure development rate, etc.

To describe this pattern, it is possible to apply the logit model of the form:

$$
V(T)=A /(1+\exp (B-C T)),
$$

Where $V$ is the average (average monthly) price of 1 sqm of the total floor area of the unit; $T$ is the number of the period (month); $A, B$ and $C$ are constant coefficients (model parameters).

In the theory of automatic control systems, such a model is used for any transient process. If the market is a self-organizing and self-regulating system, its development should fit into a similar pattern, common for either technical or socio-economic systems [6].

In the context of the above discussion, it is becoming more significant to provide strong methodological support for the real estate market analysis in the form of an economic and mathematical algorithm aimed at obtaining accurate and statistically reliable results for individual and broad real estate assessment. The theoretical grounds for such methodology have been developed and successfully applied in the last 15 years when performing analytical activities on the real estate market in Russia, and are presented in the form of an alternative methodology for market monitoring based on discrete spatial and parametric modelling $[6,7]$.

The methodology is simple to use and does not require any special knowledge from the assessors. The formalized mathematical description of discrete spatial and parametric models of the real estate market and model generation is performed within the framework of the theory of sets. This methodology can be applied for the purpose of analysing the commercial real estate market when developing a cluster system. It allows identifying strengths and weaknesses of the particular elements the commercial real estate market, which in its turn is considered the structural component of the cluster system.

The described methodology is currently being applied in 25 regions of Russia, in countries abroad Ukraine, Latvia, Azerbaijan, in Tashkent, Bishkek, Dushanbe and other capitals of the transition economy countries; it is approved at both national [3] and international [4] levels, also as a unified methodology for the countries of Central and Eastern Europe, which are the CEREAN members.

The formalized description of the procedure for generating discrete spatial and parametric models of the real estate market is performed in comparison with the approaches and concepts of a related methodology regression modelling with continuous arguments.

\section{RESULTS AND DISCUSSION}

The authors' vision of this model in its adaptation to the analysis and forecasting of the commercial real estate market development can be presented as follows.

Let $x_{i}=\in X-$ be the unit price of the $i$-commercial real estate unit or the price of $1 \mathrm{sqm}$, in the given period (the time parameter is further omitted);

$X=\left\{x_{i}\right\}, i=1,2, \ldots n$ is the discrete set of unit price values (2). 
The equation (2) is a model of source market information - the initial data for building a model of the real estate market.

The market price of a real estate unit depends on its characteristics

$\xi_{\mathrm{j}}: \mathrm{x}_{\mathrm{i}}=\mathrm{S}\left(\xi_{\mathrm{j}}\right)(3)$, where $\mathrm{S}$ is the connecting operator.

The characteristics can be continuous and discrete quantities and can be expressed in:

- a number (floor area of the real estate unit, Cartesian coordinates of the location, distance to the nearest transport facilities, etc.);

- a number range (construction period, marketing time of the real estate unit, etc.);

- a quantitative parameter (number of stories in a building, the story of the unit, the number of parking spaces in the parking lot, etc.);

- a qualitative parameter (the material of load carrying structures, material of cladding and partitions, inner layout, window orientation, etc.);

- binary "yes-no" parameter (fencing and premises security, landscaping and area improvements, maintenance state (reconstruction, overall reconditioning, etc.), vehicular access, etc.).

All the characteristics of real estate units can be broken down into groups according to three classification parameters - quality, location, and size:

$T=\left(\xi_{j T}\right)$ - a set of characteristics related to the quality of the real estate unit (design and technical specifications of the real estate unit, comfort parameters, etc.), which have an impact on the price and buyers' preferences;

$M=\left(\xi_{j M}\right)$ - a set of characteristics related to the location of the real estate unit, which have an impact on the price and buyers' preferences;

$R=\left(\xi_{j R}\right)$ - a set of characteristics related to the size of the real estate unit, which have an impact on unit price.

Then:

$X \Rightarrow\left\{x_{i}\left(\xi_{j T}, \xi_{j M}, \xi_{j R}\right)\right\}$.

Numerical values of the characteristics above should be divided into ranges and converted to discrete ones. Then:
In regression theory of regression analysis, the characteristics of an object are referred to as factors. Based on market information, a continuous discrete model of the market is built $X=F\left(\xi_{i}\right)$, and according to statistical criteria, the levels of factor significance are set. Criterion factor values are set by the evaluator. The factors that meet these criteria are considered significant, while the rest are considered random. The regression model is constructed as the average of random factors (as it has been mentioned above, usually there are 5-10 significant factors out of the initial 20-30 factors). Sometimes the evaluator may switch to a discrete model for individual factors, dividing their variation range into subranges (steps) by significant price change at each (not necessarily equal) step. The total number of ranges equals the sum of ranges of each factor. Thus, for example, 10 factors with the value of each divided into three ranges make a matrix of 30 values. Further, the total number of permutations of range values corresponds to the theoretically possible number of unit description combinations (in practice, when constructing regression models for broad assessment, it may reach several hundred). Analogous procedures, though different in form, are used when building discrete models. Firstly, a group of parameters of the quality of the real estate unit should be addressed

Let us group characteristics of quality so that the entirety of ranges and/or features of all significant characteristics forms a physically definable set that corresponds to a subset of the elements of the given set (6):

$$
\begin{aligned}
& \left\{x_{i t 1}\right\}=\left\{x_{i} / \xi_{t}=\left\{\xi_{t 1}\right\}\right\} ; \\
& \left\{x_{i t 2}\right\}=\left\{x_{i} / \xi_{t}=\left\{\xi_{t 2}\right\}\right\} ;
\end{aligned}
$$

or

$$
\cup x_{i t}=x_{i t 1} \cup x_{i t 2} \cup \ldots
$$

Let us call subset $\left\{x_{i t j}\right\}$ of physically definable variants of the combination of characteristics "unit type" $T_{i}$. Then:

$$
\begin{aligned}
& X_{T 1}=\left\{x_{i t 1}\right\}, \ldots \\
& X_{T 2}=\left\{x_{i t 2}\right\}, \ldots
\end{aligned}
$$

Subsequently, $X_{T}=\left\{X_{T 1}, X_{T 2}, \ldots\right\}-$ a set of subsets that combine units of the same type. (7)

Similarly, the characteristics (coordinates) of the location of the real estate unit are reduced to discrete ones:

$$
\begin{aligned}
& \left\{x_{i m 1}\right\}=\left\{x_{i} / \xi_{m}=\left\{\xi_{m 1}\right\}\right\} ; \\
& \left\{x_{i m 2}\right\}=\left\{x_{i} / \xi_{m}=\left\{\xi_{m 2}\right\}\right\} ;
\end{aligned}
$$




$$
\text { or } \cup x_{i m}=x_{i m 1} \cup x_{i m 2} \cup \ldots .
$$

Let us call subset $\left\{\xi_{m i}\right\}$ "area (district) of the location of the unit" $M_{i}$. Then:

$$
\begin{aligned}
& X_{M 1}=\left\{x_{i m 1}\right\}, \ldots \\
& X_{M 2}=\left\{x_{i m 2}\right\}, \ldots
\end{aligned}
$$

Subsequently, $X_{M}=\left\{X_{M 1}, X_{M 2}, \ldots\right\}-$ a set of subsets that combine units of the same location (11).

The size characteristics of the real estate unit are most typically described by the discrete indicator "number of units". Sometimes the size of the unit can be set by the value of the total floor area and can be converted to a discrete form by assigning ranges of the total floor area of the unit. In the general case:

$$
\begin{aligned}
& \left\{x_{i r 1}\right\}=\left\{x_{i} / \xi_{r}=\left\{\xi_{r 1}\right\}\right\} ; \\
& \left\{x_{i r 2}\right\}=\left\{x_{i} / \xi_{r}=\left\{\xi_{r 2}\right\}\right\} ;
\end{aligned}
$$

or

$$
\cup x_{i r}=x_{i r 1} \cup x_{i r 2} \cup \ldots .
$$

Let us call subset $\left\{\xi_{\mathrm{ri}}\right\}$ "size of the unit" $\mathrm{R}_{\mathrm{i}}$. Then:

$$
X_{R l}=\left\{x_{i r l}\right\}, \ldots
$$$$
X_{R 2}=\left\{x_{i r 2}\right\}, \ldots
$$

Subsequently, $X_{M}=\left\{X_{R 1}, X_{R 2}, \ldots\right\}-$ a set of subsets that combine units of the same size (15).

Finally, combining sets allows grouping real estate units according to the combination of type, area (district) and size:

$$
X=X_{T} \cup X_{M} \cup X_{R} ; \cap X_{T} \cap X_{M} \cap X_{R}=\varnothing ;
$$

$$
X=\left\{\left\{x_{\text {TIMIRI }}\right\},\left\{x_{\text {T2MIRI }}\right\}, \quad \ldots \quad\right\} .
$$

The condition above (21) states that the intersection of sets (13) - (17) is the empty set. In practice, the initial data on the characteristics of the real estate unit might be incomplete, and the unit may not be classified into any of the identified types, locations, or sizes. If so, they should be classified into the "Other" type (zone, size) category to meet the condition (18).

In terms of regression models of broad assessment, expression (19) is called the specification of the model of the real estate market. The next step is model calibration or obtaining quantitative estimation of model parameters.

In terms of discrete spatial and parametric models, this procedure implies statistical analysis of samples (19) and setting the main parameters of the sample volume $\mathrm{n}$, average $\mathrm{x}_{\mathrm{av}}$, range of deviation $\mathrm{x}_{\min \text {. }}$ and $\mathrm{x}_{\max }$, variance $D$, average error $\delta$. The result is the initial discrete spatial and parametric model of the real estate market [8]:

$$
\begin{aligned}
& X=\left\{\left\{\left(n, x_{a v}, x_{\text {min. }}, x_{\text {max }}, D, \delta\right)_{\text {TIMIRI }}\right\},\right. \\
& \left.\left.\left.n, x_{a v}, x_{\text {min. }}, x_{\text {max. }}, D, \delta\right)_{T 2 M I R I}\right\}, \ldots\right\} .
\end{aligned}
$$

The next operation in building a discrete spatial and parametric model of the real estate market is its adjustment and optimization. Adjustment starts with checking the sample size.

In practice, units of some type might not be available on the market in a particular territory. If so, the corresponding row is omitted from the matrix.

The sample volume of a given type in a particular area might also not be sufficient. If so, this sample is to be combined with the sample of a geographically close area, and the parameters of the updated sample are recalculated. Model optimization starts with checking the sampling range and variance. The condition for optimization is minimizing the range of each sample with approximate equality of variation coefficient $v$ :

$$
\begin{aligned}
& \left(x_{\text {max. }}-x_{\text {min. }}\right) \rightarrow \text { min.; } \\
& v_{i}=\sqrt{ } D_{i} / x_{c p . i} \approx \text { const } .
\end{aligned}
$$

Reducing the sampling range can be performed through dividing it into two samples by introducing an additional parameter or dividing the range of any parameter. For instance, if the sample of retail space in shopping centres the range of variation is too wide, it is advisable to divide it into two subtypes - retail space in central and side alleys.

The next optimizing procedure has the opposite focus- it is aimed at checking the feasibility of sample combination. For this purpose, a pairwise test of statistical significance of samples by type, size, and areas is performed. It implies checking the difference between variances (Fisher's test $F_{p}$ ) and average (Student's test $t_{p}$ ) for given criterion values of the significance level $\mathrm{p}$ chosen by the evaluator. This procedure corresponds to a similar procedure of testing statistical significance within regression modelling.

The samples with insignificant differences are combined and the parameter values are recalculated. In practice, there can be a simpler condition for combining samples 1 and 2 .

$$
x_{a v .1}+\delta_{1} / 2>x_{a v .2}-\delta_{2} / 2\left(\text { when } x_{a v .1}<x_{a v .2}\right) .
$$

This transformation corresponds to down weighting of the regression model and omitting the insignificant parameters of quality, location and size of real estate unit.

The result is the discrete spatial and parametric model of the commercial real estate market, the excerpt 
of which by the example of Pyatigorsk is presented in "Table I".

TABLE I. THE EXCERPT OF THE DISCRETE SPATIAL AND PARAMETRIC MODEL OF THE COMMERCIAL REAL ESTATE OF PYATIGORSK (CALCULATED BY THE AUTHORS ACCORDING TO THE PROPOSED MODEL)

\begin{tabular}{|l|l|l|l|l|l|}
\hline \multicolumn{7}{|c|}{ District } & \multicolumn{1}{|c|}{ All } & \multicolumn{1}{|c|}{ Centre } & Impulse & $\begin{array}{c}\text { Belaya } \\
\text { Romashka }\end{array}$ & \multicolumn{1}{c|}{ Other } \\
\hline \multicolumn{7}{|c|}{ Alts } \\
\hline Number & 1,305 & 450 & 315 & 120 & 420 \\
\hline Average unit price & 47,000 & 54,000 & 47,000 & 38,000 & 34,000 \\
\hline Min price & 15,000 & 16,000 & 15,000 & 15,000 & 19,000 \\
\hline Max price & 130,000 & 130,000 & 70,000 & 90,000 & 48,000 \\
\hline
\end{tabular}

Thus, the developed methodology for monitoring the real estate market consists in collecting documented information about the real estate market units, dividing them into homogeneous groups (samples) according to their quality, location, size and other characteristics (including their cluster affiliation (forecasted affiliation), identifying the statistical characteristics of each sample and analysing the obtained numerical spatial and parametric models with a discrete step. Discrete spatial and parametric models can further be used as source data for developing a model of a tourist and recreational and trade and logistics clusters, comparing their performance indicators over time, or for a comparative analysis of the performance of several cluster structures in the analysed territory. For instance, "Table I" shows that shopping facilities in the centre of Pyatigorsk have greater prospects of being included into the cluster, since they are characterized by a higher occupancy rate and steady demand. Moreover, the analysis of price behaviour highlights a positive trend, which indicates the growing investment attractiveness of shopping facilities in this district of the city.

The described methodology is rather simple, and using it does not require special education. The mathematical foundations behind the methodology outlined above, have been practically approved by Russian specialists and are presented in their works [4], [8], [9].

In order to build discrete spatial and parametric models, the units of retail and warehousing real estate, as mentioned earlier, are subject to typification. The tables below consider the typification of these real estate units by quality ("Table II" and "Table IV") and by size ("Table III" and "Table V") [10].

TABLE II. TYPIFICATION OF COMMERCIAL PREMISES BY QUALITY

\begin{tabular}{|c|l|l|l|}
\hline Type index & \multicolumn{1}{|c|}{ Type } & Parameters & Value \\
\hline $\mathbf{1}$ & Retail shopping centre & & \\
\hline $\mathbf{2}$ & Separate building & & \\
\hline $\mathbf{3}$ & Ground floor in residential buildings & & \\
\hline $\mathbf{4}$ & Annex to the building & & \\
\hline $\mathbf{5}$ & Concession stand & & \\
\hline $\mathbf{6}$ & Stall & & \\
\hline $\mathbf{7}$ & $\begin{array}{l}\text { Unfitted premises in administrative } \\
\text { buildings }\end{array}$ & & \\
\hline etc. & $\ldots$ & $\ldots$ & \\
\hline
\end{tabular}

TABLE III. TYPIFICATION OF COMMERCIAL PREMISES BY SIZE

\begin{tabular}{|c|l|}
\hline Size index & \multicolumn{1}{|c|}{ Floor area, sqm } \\
\hline $\boldsymbol{a}$ & under 100 \\
\hline $\boldsymbol{b}$ & $100-200$ \\
\hline $\boldsymbol{c}$ & $200-600$ \\
\hline $\boldsymbol{d}$ & over 600 \\
\hline
\end{tabular}


TABLE IV. TYPIFICATION OF WAREHOUSES BY QUALITY

\begin{tabular}{|c|c|c|c|}
\hline Type index & Type & Parameters & Value \\
\hline \multirow{3}{*}{1} & \multirow{3}{*}{$\begin{array}{l}\text { Professional } \\
\text { warehouse } \\
\text { complex, class A }\end{array}$} & Mechanization & Fully-mechanized \\
\hline & & Spur track & Available \\
\hline & & Access trestles or ramps & Available \\
\hline \multirow{3}{*}{2} & \multirow{3}{*}{$\begin{array}{l}\text { Professional } \\
\text { warehouse, class } \\
\text { B }\end{array}$} & Mechanization & Crane equipment \\
\hline & & Spur track & Not available \\
\hline & & Access trestles or ramps & Available \\
\hline \multirow{3}{*}{3} & \multirow{3}{*}{$\begin{array}{l}\text { Professional } \\
\text { warehouse, class } \\
\text { C }\end{array}$} & Mechanization & Pellet jacks and forklifts \\
\hline & & Spur track & Not available \\
\hline & & Access trestles or ramps & Available \\
\hline \multirow{3}{*}{4} & \multirow{3}{*}{$\begin{array}{l}\text { Warehouse in } \\
\text { fitted premises, } \\
\text { class D }\end{array}$} & Mechanization & Not available \\
\hline & & Spur track & Not available \\
\hline & & Access trestles or ramps & Not available \\
\hline \multirow{3}{*}{5} & \multirow{3}{*}{$\begin{array}{l}\text { Warehouse in } \\
\text { unfitted premises, } \\
\text { class E }\end{array}$} & Mechanization & Not available \\
\hline & & Spur track & Not available \\
\hline & & Access trestles or ramps & Not available \\
\hline etc. & $\ldots$ & $\ldots$ & \\
\hline
\end{tabular}

TABLE V. TYPIFICATION OF WAREHOUSES BY SIZE

\begin{tabular}{|c|l|}
\hline Size index & \multicolumn{1}{c|}{ Floor area, sqm } \\
\hline $\boldsymbol{a}$ & under100 \\
\hline $\boldsymbol{b}$ & $100-1,000$ \\
\hline $\boldsymbol{c}$ & $1,000-10,000$ \\
\hline $\boldsymbol{d}$ & over 10,000 \\
\hline
\end{tabular}

Thus, based on the results of the study, the models for analysing the real estate market within the context of its integration into the process of territorial clustering can be classified into the following groups according to:

- the temporal factor: static and dynamic.

- the number of market participants: perfect competition, monopolistic competition, oligopoly and monopoly.

- the principle of differentiation: spatial, temporal and comparative.

- the modelling object: primary market model, secondary market model, commercial real estate market model, etc.
The authors suggest considering the examples of various models of the real estate market in the Caucasian Mineralnye Vody region. The dynamic model of the real estate market of the Caucasian Mineralnye Vody region is presented in "Table VI".

As stated in the dynamic model calculated by the authors, since January to July 2019, the average unit price of 1 sqm of retail space across Pyatigorsk increased by $4.4 \%$ (the incremental price).

In order to compare the prices in different districts of the city, a spatial model of the real estate market analysis should be applied. It should be mentioned that for the real estate market specialists, the district can be considered as a conditional territory and include several administrative districts of the city.

TABLE VI. DYNAMICS OF THE AVERAGE UNIT PRICE OF COMMERCIAL REAL ESTATE IN PYATIGORKS, 2019 (CALCULATED BY THE AUTHORS BASED ON THE DATA ON THE REAL ESTATE MARKET OF PYATIGORSK)

\begin{tabular}{|c|l|l|l|l|l|l|l|l|l|}
\hline & \multicolumn{1}{|c|}{ Jan 17 } & \multicolumn{1}{|c|}{ Dec 17 } & \multicolumn{1}{|c|}{ Jan18 } & \multicolumn{1}{|c|}{ Mar 18 } & \multicolumn{1}{|c|}{ Apr 18 } & \multicolumn{1}{|c|}{ May 18 } & Jun18 & Jul 18 & $\begin{array}{c}\text { Min-Max } \\
\text { July }\end{array}$ \\
\hline $\begin{array}{c}\text { Average } \\
\text { unit price, } \\
\text { RUB/sqm }\end{array}$ & 54,000 & 46,000 & 45,000 & 46,000 & 46,000 & 47,000 & 48,000 & 47,000 & $\begin{array}{l}15,000- \\
130,000\end{array}$ \\
\hline Change & $100 \%$ & $85 \%$ & $83 \%$ & $85 \%$ & $85 \%$ & $87 \%$ & $89 \%$ & $87 \%$ & - \\
\hline
\end{tabular}

"Fig. 1" presents the price difference of 1 sqm of commercial real estate in different areas of the city and reveals its correlation when classifying the sample objects according to the location criterion. Thus, for 
instance, the price of $1 \mathrm{sqm}$ of commercial real estate in the Centre is 1.59 times higher than in the city districts in the sub-sample "Other".

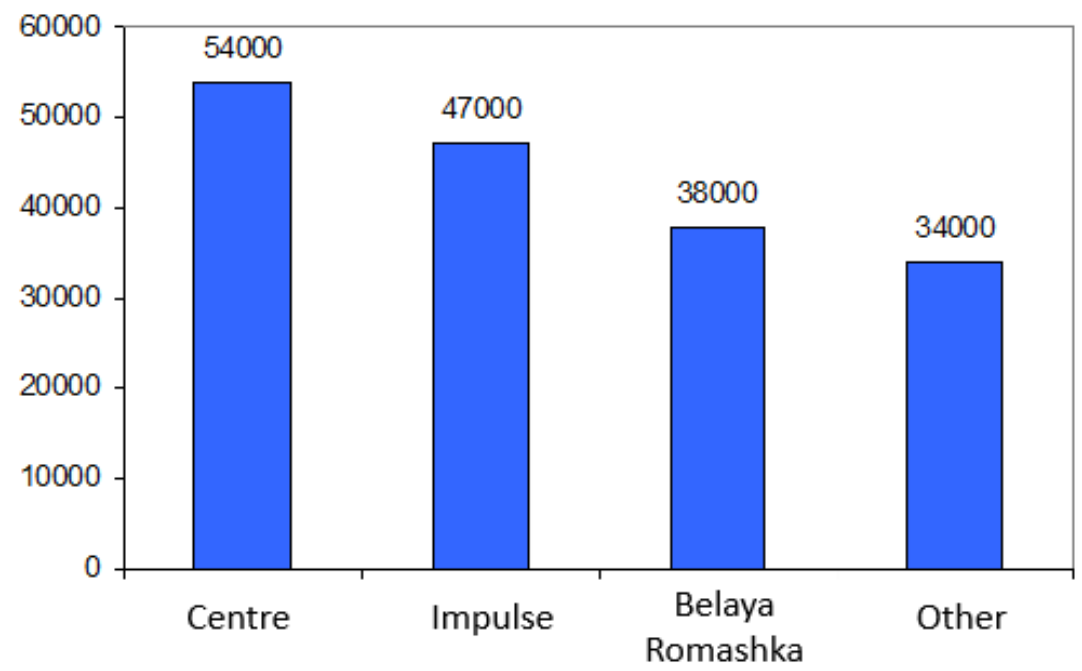

Fig. 1. Average offer price of $1 \mathrm{sqm}$ of commercial real estate in the districts of Pyatigorsk (Calculated by the authors based on the data on the real estate market of Pyatigorsk).

Thus, the instruments for modelling the real estate market in general and the commercial real estate market in particular are well-developed and rather effective. They provide the opportunity to monitor, analyse and forecast the real estate market; the obtained results can be further applied to assess the socio-economic position of the territory and the prospects for its cluster development.

\section{CONCLUSION}

In the course of the study, the following conclusions have been made:

- When performing the assessment of the commercial real estate, it is essential to apply the characteristics of real estate that can be expressed in the form of continuous and discrete values and can be classified according to quality, location, and size.

- The developed methodology for monitoring the real estate market consists in collecting documented information about the real estate market units, dividing them into homogeneous groups (samples) according to their quality, location, size and other characteristics (including their cluster affiliation (forecasted affiliation), identifying the statistical characteristics of each sample and analysing the obtained numerical spatial and parametric models with a discrete step.

\section{References}

[1] Anisimova I.N., Barinov N.P., Gribovsky S.V. On the requirements for the number of comparable objects when evaluating real estate, a comparator with a comparative approach. Valuation issues No. 1. 2003. Pp. 2-7.

[2] Bondarchuk S.L. Testing of the mass real estate valuation system in the constituent entities of the Russian Federation. Presentation at a seminar at the Institute of Real Estate of the Higher School of Economics on October 16, 2009. Pp. 9-15.

[3] Fedotova M.A., Gribovsky S.V., Sternik G.M. and others. The development of methodology for broad appraisal of the market value of apartments for tax purposes. Report. 2004. Pp. 74-82.

[4] Sternik G.M. and others. The concept of the Federal Information and Analytical System of the housing market". Report. 2001. Pp. 112-134.

[5] Sternik G.M., Nozdrina N.N., Kaminskiy V.N. and others. Housing market of Russia in 1994. Analysis and forecast Report. Moscow. 1995. 135 p.

[6] Sternik G.M. The common methodology for calculating real estate market indices for the countries - CEREAN members. CEREAN Conference Report. Kiev, September 2005. Pp. 35-48.

[7] Sternik G.M. Methodical recommendations for the analysis of the real estate market. 1998. $60 \mathrm{p}$.

[8] Sternik G.M. The technology for the real estate market analysis. Moscow. AXWELL. 2006. 203 p.

[9] Gusev A.F., Sternik G.M. Real estate market indices. Scientific electronic journal. 2000. No.1. Pp.25-37.

[10] Gribovsky S.V., Fedotova M.A., Sternik G.M., Zhitkov D.B. Methodology of broad appraisal of apartments for taxation. Bulletin of financial information. No. 1 (116). 2005. Pp. 14-29. 